\title{
HUBUNGAN KINERJA OTAK DENGAN SPIRITUALITAS MANUSIA DIUKUR DENGAN MENGGUNAKAN INDONESIA SPIRITUAL HEALTH ASSESSMENT PADA PEMIMPIN AGAMA DI KOTA TOMOHON
}

\author{
${ }^{1}$ Jendy Cliff Dadana \\ ${ }^{2}$ Taufik F. Pasiak \\ ${ }^{2}$ Sunny Wangko \\ ${ }^{1}$ Kandidat Skripsi Fakultas Kedokteran Universitas Sam Ratulangi Manado \\ ${ }^{2}$ Bagian Anatomi-Histologi Fakultas Kedokteran Universitas Sam Ratulangi Manado \\ Email: jendycliff@gmail.com
}

\begin{abstract}
Neuroscience is a science about the nervous system or neurons. The development of neuroscience has touched the spiritual dimension. There are four things if being combined will result in spirituality, as follows: meaning of life, positive emotions, spiritual experiences, and rituals. By using SPECT, Daniel Amen divided the brain into five major systems namely prefrontal cortex, limbic system, basal ganglia, gyrus cingulatus, and temporal lobes. All these five systems have correlation with spirituality. There are tools that can measure and describe the correlation of spirituality with brain inter alia Indonesia Spiritual Health Assessment (ISHA). This study aimed to determine the correlation between the brain performance with the spirituality in religious leaders in Tomohon city. This was a descriptive study with analytical survey method. Samples were 51 GMIM priests. Data of this study were analyzed by using the Spearman correlation test. The results showed that the average value of the brain, especially the limbic system, was 5.80 (good), where as the spirituality, especially ritual, was 155.50 (very good). The Spearman Correlation test showed a $P$-value $=0,013$, which means the correlation between the two variables was significant. Conclusion: There was a significant correlation between the brain performance and the human spirituality measured by using ISHA in religious leaders at Tomohon City.
\end{abstract}

Keywords: brain, ISHA, religious leaders, spirituality

\begin{abstract}
Abstrak: Neurosains adalah ilmu yang mempelajari tentang sel saraf atau neuron. Perkembangan neurosains telah menyentuh dimensi spiritual. Terdapat empat hal yang bila digabungkan akan menghasilkan spiritualitas yaitu makna hidup, emosi positif, pengalaman spiritual, dan ritual. Melalui jasa SPECT, Daniel Amen membagi otak dalam lima sistem utama yaitu: korteks prefrontalis, sistem limbik dalam, ganglia basalis, girus singulatus, dan lobus temporalis. Kelima sistem ini memiliki hubungan dengan spiritualitas. Alat yang dapat mengukur spiritualitas serta menggambarkan hubungannya dengan otak, antara lain ialah Indonesian Spiritual Health Assessment (ISHA). Penelitian ini bertujuan untuk mengetahui hubungan kinerja otak dan spiritualitas pada pemimpin agama di kota Tomohon. Penelitian ini bersifat deskriptif dengan metode survei analitik. Sampel penelitian ialah pendeta-pendeta GMIM dengan jumlah 51 orang. Data penelitian dianalisis menggunakan uji korelasi Spearman. Nilai rata-rata otak khususnya sistem limbik yaitu 5,80 (baik), sedangkan spiritualitas khususnya ritual yaitu 155,50 (sangat baik). Hasil uji korelasi Spearman menunjukkan nilai $P=0,013$ yang berarti hubungan kedua variabel bermakna. Simpulan: Terdapat hubungan bermakna antara kinerja otak dan spiritualitas manusia diukur dengan menggunakan ISHA pada pemimpin agama di kota Tomohon.
\end{abstract}

Kata kunci: ISHA,otak, pemimpin agama, spiritualitas. 
Neurosains merupakan bidang ilmu yang secara khusus mempelajari tentang sel-sel saraf atau neuron. ${ }^{1}$ Ilmu ini mempelajari segala sesuatu tentang otak manusia, mengkaji unsur-unsur biologisnya, serta mempelajari proses hubungan manusia dengan Tuhan. ${ }^{1,2}$ Neurosains merupakan gabungan banyak sekali bidang keahlian, ilmuwan, dan objek penelitian yang berkaitan dengan otak. ${ }^{3}$ Saat ini pendekatan neurosains telah menyentuh dimensi spiritual, yang lebih dikenal dengan istilah neurosains spiritual.I stilah ini dipakai untuk menjelaskan spiritualitas manusia dipandang dari sisi perspektif kesehatan dan kedokteran. Neurosains spiritualitas ini sangat penting bila dikaitkan dengan UU Kesehatan RI Nomor 36/2009 yang mengartikan kesehatan sebagai keadaan sehat secara fisik, mental, spiritual, dan sosial. ${ }^{4-5}$

Spiritualitas merupakan keyakinan yang berkaitan dengan Yang Maha Kuasa dan Maha Pencipta. ${ }^{6}$ Spiritualitas merupakan bagian penting dari kesehatan karena diduga dapat berperan sebagai penyembuh dari segala macam penyakit. ${ }^{7}$ Penelitian Kinarsih dan Wahyuningsih ${ }^{8}$ menunjukkan bahwa pasien lansia di RS Baptis Kediri dengan pendampingan spiritual memiliki motivasi kesembuhan yang sangat tinggi, sehingga mendukung asuhan keperawatan yang diberikan. Mabena dan Moodley ${ }^{9}$ meneliti pasien kanker serviks di Afrika dan mendapatkan bahwa banyak pasien mengaitkan kesembuhannya dengan spiritual yang dimilikinya. Pasien tersebut mengakui adanya kesulitan hidup dalam keadaan sakit, namun spiritualitas memungkinkannya untuk mengatasi kesulitan tersebut.

Sifat dan perilaku spiritual, pengalaman spiritual, emosi positif, dan ritual memiliki pengaruh yang luar biasa dalam banyak hal, khususnya di bidang kesehatan. Hasil riset menunjukkan bahwa individu yang hidup dengan komponen-komponen spiritual memiliki kehidupan yang relatif sehat dan lebih bahagia. Sampai saat ini dimensi spiritual masih kurang diperhatikan dalam dunia kesehatan. Sebagai contoh, dalam pemeriksaan kesehatan baik untuk kepentingan pemetaan ataupun untuk tes kelayakan, dimensi spiritualitas sering diabaikan. $^{3,10}$

Kegiatan spiritual dalam otak manusia merupakan hasil kerja dari sejumlah komponen otak yang dinamakan operator kognitif. Komponen otak ini bekerja untuk menghasilkan pengalaman spiritual. Operator kognitif terdiri dari korteks prefrontalis, area asosiasi, sistem limbik, dan sistem saraf otonom. ${ }^{3}$

Berbagai penelitian menunjukkan fungsi spiritual bersumber dari dalam otak. Penelitian-penelitian ini menghadirkan adanya pengukuran dan pemeriksaan terhadap spiritualitas serta hubungannya dengan otak, salah satunya Indonesian Spiritual Health Assessment (ISHA). Alat ukur ini dibuat berdasarkan konsep-konsep teoritis spiritualitas. ISHA berbentuk kuesioner dan terdiri dari tiga komponen yaitu spiritual health item, brain system assessment, dan neurofeedback. ${ }^{3,11}$

Pemimpin agama atau pemimpin spiritual merupakan orang-orang yang memimpin kegiatan agama tertentu. Pemimpin agama dan pengikutnya mempelajari halhal spiritual. Dengan aktifitas yang selalu berkaitan dengan spiritual, pemimpin agama diyakini memiliki spiritualitas yang tinggi. ${ }^{12}$ Saat ini banyak pemimpin agama yang mulai diragukan spiritualitasnya. Kasus-kasus yang melibatkan para pemimpin agama menunjukkan kemungkinan adanya ketidaklarasan hubungan antara kerja otak dengan spiritualitas pemimpin agama tersebut.

Sampai saat ini, di Sulawesi Utara khususnya di Tomohon belum pernah dilaporkan penelitian tentang hubungan otak dan spiritualitas. Dengan adanya penelitian seperti ini, dapat dinilai baik buruknya kinerja otak dan spiritualitas seseorang khususnya para pemimpin agama yang menjadi panutan dalam kehidupan beragama.

\section{METODE PENELITIAN}

Penelitian ini bersifat deskriptif dengan metode survei analitik. Tempat 
penelitian dilakukan di kota Tomohon dengan waktu penelitian selama satu bulan yaitu bulan November 2012-Desember 2012. Populasi dalam penelitian ini ialah pemimpin agama Kristen Protestan khususnya Pendeta GMIM di kota Tomohon yang berjumlah 104 orang, dengan jumlah sampel 51 orang yang didapatkan dengan menggunakan rumus Slovin yaitu:

$$
\begin{aligned}
& \mathrm{n}=\mathrm{N} / 1+\mathrm{N} \cdot \mathrm{d}^{2} \\
& \mathrm{n}=104 / 1+104 \cdot 0,1^{2} \\
& \mathrm{n}=50,9 \text { (dibulatkan } 51 \text { orang) }
\end{aligned}
$$

Variabel dalam penelitian yaitu otak sebagai variabel bebas dan spiritualitas sebagai variabel terikat. Pengumpulan data dilakukan dengan menggunakan kuesioner ISHA, sedangkan analisis data menggunakan uji korelasi Spearman oleh karena jenis datanya merupakan jenis data ordinal.

\section{HASIL PENELITIAN}

Responden yang menjadi subjek penelitian ialah pendeta-pendeta GMIM di kota Tomohon. Sampel yang digunakan dalam penelitian ini berjumlah 51 orang.

\section{Karakteristik responden}

Usia responden dikelompokkan menjadi dua kelompok yaitu responden dengan usia $<40$ tahun dan responden dengan kelompok usia $>40$ tahun. Kelompok usia $>40$ tahun memilki persentase lebih banyak dibandingkan kelompok usia $<40$ tahun. Bila dilihat dari jenis kelamin, responden perempuan (68\%) lebih banyak dibandingkan laki-laki (31,4\%) (Tabel 1).

Berdasarkan kelompok usia, persentase responden kelompok usia $<40$ tahun berjumlah 17,6\% dengan jumlah responden laki-laki 2\% sedangkan jumlah responden perempuan 15,6\%. Pada kelompok usia $>40$ tahun, terdapat $82,4 \%$ responden yang ikut dengan jumlah responden laki-laki 29,4\% sedangkan jumlah responden perempuan 53\% (Tabel 1).

\begin{tabular}{|c|c|c|c|}
\hline \multirow{2}{*}{$\begin{array}{c}\text { Kelompok } \\
\text { usia } \\
\text { (tahun) }\end{array}$} & \multicolumn{2}{|c|}{ Jenis Kelamin } & \multirow[b]{2}{*}{$\begin{array}{c}\text { Jumlah } \\
(\%)\end{array}$} \\
\hline & $\begin{array}{l}\text { Laki- } \\
\text { laki } \\
(\%)\end{array}$ & $\begin{array}{l}\text { Perempuan } \\
\text { (\%) }\end{array}$ & \\
\hline$<40$ & 2 & 15,6 & 17,6 \\
\hline$>40$ & 29,4 & 53 & 82,4 \\
\hline Total & 31,4 & 68,6 & 100 \\
\hline
\end{tabular}

Tabel 1. Distribusi responden berdasarkan kelompok usia dan jenis kelamin.

\section{Hasil interpretasi ISHA}

Terdapat tida kategori untuk interpretasi ISHA, yaitu: excellent (sangat baik), moderate (baik), dan improved (cukup baik). Hasil ISHA dominasi otak yang meliputi korteks prefrontalis, sistem limbik, ganglia basalis, girus singulatus, serta lobus temporalis umumnya memiliki interpretasi excellent dan moderate. Nilai rata-rata responden perempuan lebih banyak dibandingkan responden laki-laki oleh karena jumlah responden perempuan yang ikut lebih banyak dari responden lakilaki. Responden dengan interpretasi improved memiliki jumlah yang sangat sedikit (Gambar 1).

Nilai rerata dominasi otak tertinggi pada ganglia basalis diikuti oleh korteks prefrontalis, sistem limbik, lobus temporalis, dan girus singulatus. Intepretasi nilai rerata korteks prefrontalis, ganglia basalis, girus singulatus, dan lobus temporalis pada responden yaitu excellent (sangat baik), sedangkan interpretasi nilai rerata sistem limbik yaitu moderate (Tabel 2).

Hasil ISHA spiritualitas yang meliputi pengalaman spiritual, emosi positif, makna hidup, serta ritual umumnya memiliki interpretasi excellent, dan hanya beberapa responden dengan interpretasi moderate (Gambar 2).

Nilai rerata hasil ISHA spiritualitas tertinggi pada ritual diikuti oleh makna hidup, emosi positif, dan terakhir pengalaman spiritual. Interpretasi nilai ratarata pengalaman spiritual yaitu moderate, sedangkan interpretasi nilai rata-rata pada emosi positif, makna hidup, dan ritual yaitu excellent (Tabel 3). 


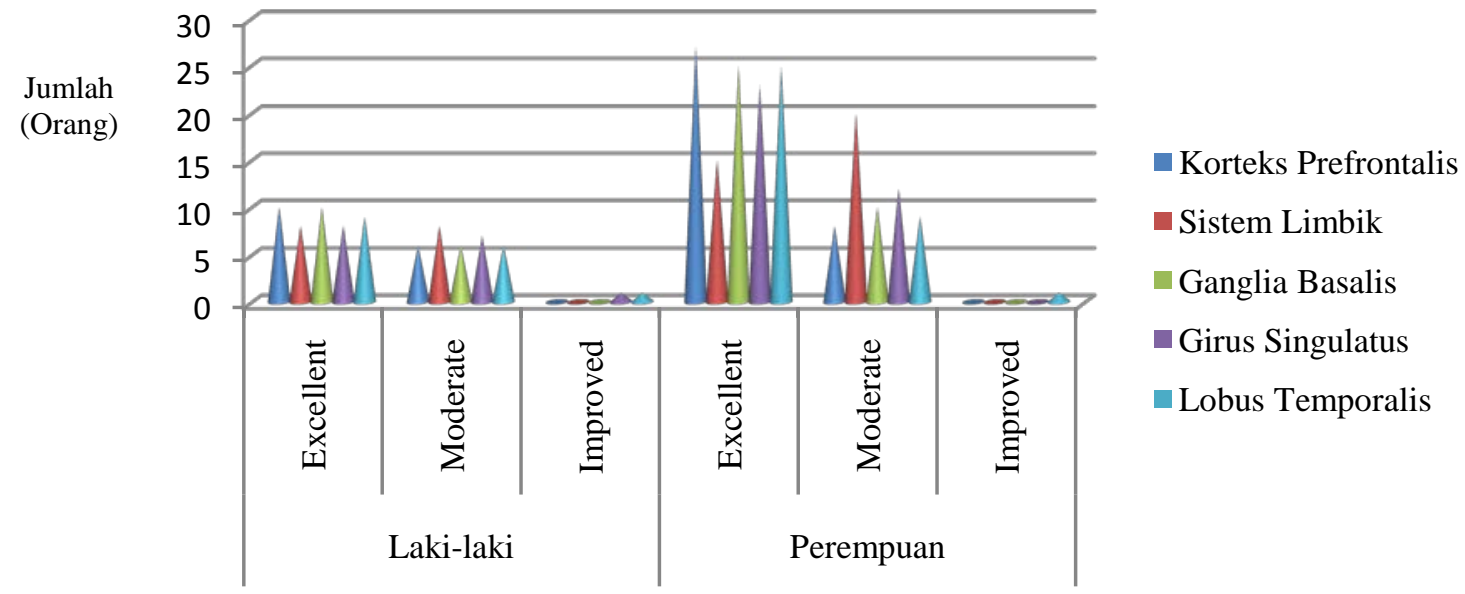

Gambar 1. Hasil ISHA dominasi otak berdasarkan jenis kelamin.

Tabel 2. Nilai rerata hasil ISHA dominasi otak

\begin{tabular}{cccccc}
\hline \multicolumn{5}{c}{ Dominasi otak } \\
\hline \multirow{2}{*}{ Indikator } & Korteks & Sistem & Ganglia & Girus & Lobus \\
& prefrontalis & limbik & basalis & singulatus & temporalis \\
Rerata & 6,64 & 5,80 & 7,11 & 3,05 & 3,76 \\
Interpretasi & Excellent & Moderate & Excellent & Excellent & Excellent \\
\hline
\end{tabular}

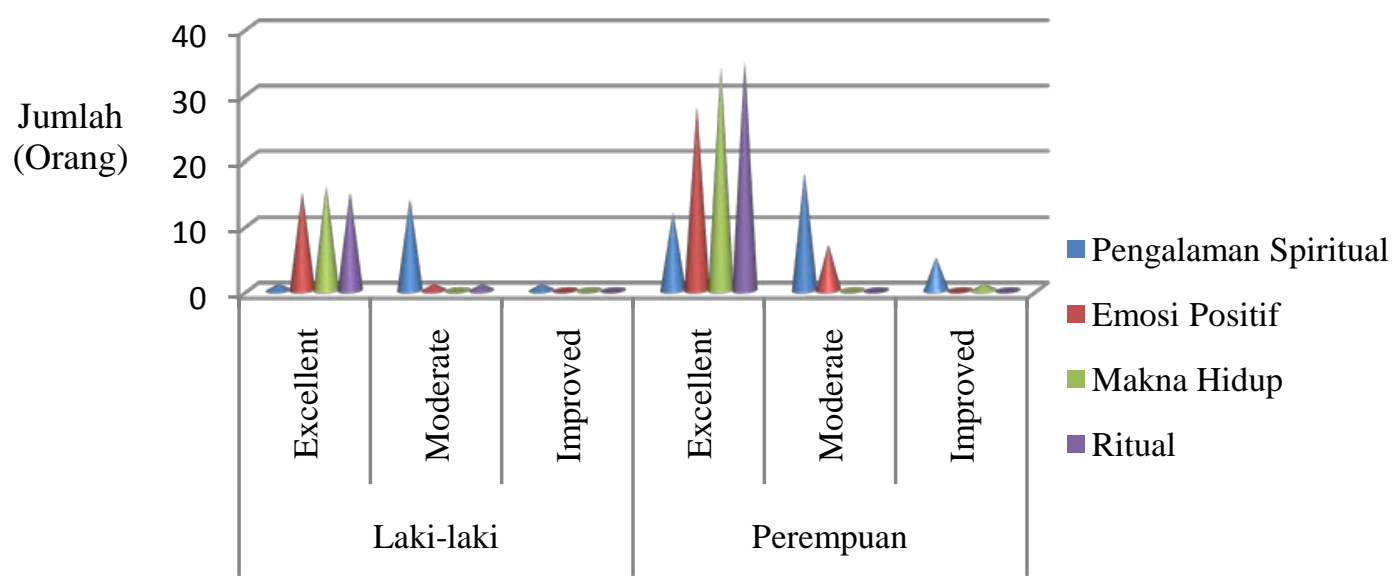

Gambar 2. Hasil ISHA spiritualitas berdasarkan jenis kelamin.

Tabel 3. Nilai rerata hasil ISHA spiritualitas

\begin{tabular}{|c|c|c|c|c|}
\hline & \multicolumn{4}{|c|}{ Spiritualitas } \\
\hline Indikator & $\begin{array}{c}\text { Pengalaman } \\
\text { spiritual }\end{array}$ & $\begin{array}{l}\text { Emosi } \\
\text { positif }\end{array}$ & $\begin{array}{c}\text { Makna } \\
\text { hidup }\end{array}$ & Ritual \\
\hline Rata-rata. & 31,86 & 36,17 & 44,80 & 155,50 \\
\hline Interpretasi & Moderate & Excellent & Excellent & Excellent \\
\hline
\end{tabular}




\section{Hasil analisis data}

Data dalam penelitian ini dianalisis menggunakan uji korelasi Spearmanpada aplikasi SPSS versi 20. Kemaknaan hubungan kedua variabel dilihat pada taraf signifikan $(P)$ dengan nilai kemaknaan $<\alpha$ $=0,05$. Untuk nilai koefisien korelasi $(\mathrm{r})$ berada diantara -1 dan +1 dimana bila nilai r mendekati -1 berarti kedua variabel memiliki hubungan negatif yang kuat sedangkan bila nilai $\mathrm{r}$ mendekati +1 berarti kedua variabel memiliki hubungan positif yang kuat (Tabel 4).

Hasil uji korelasi antara otak dan spiritualitas dalam hal ini sistem limbik dan ritual didapatkan $P=0,013$ yang berarti terdapat hubungan bermakna antara kedua variabel. Untuk nilai koefisien korelasi didapatkan -0,346. Nilai ini menunjukkan bahwa hubungan kedua variabel lemah dengan pola negatif (Tabel 4).

\section{BAHASAN}

Dari hasil penelitian ini didapatkan bahwa hubungan kerja sistem limbik dan dimensi ritual pada kehidupan responden masih berjalan dengan baik (Tabel 4). Hasil ini menunjukkan bahwa responden merupakan individu yang aktif dalam melakukan bentuk-bentuk ritual, sebagai contoh: melakukan sembahyang, memanjatkan doa, mengunjungi tempat ibadah, memberi sedekah, dan terlibat aktif dalam komunitas keagamaan. $^{3}$

Tabel 2 dan Tabel 3 yang memuat hasil rata-rata dominasi otak dan spiritualitas menunjukkan bahwa sistem limbik dan ritual pada responden memiliki interpretasi baik. Hasil ini menunjukkan adanya keterkaitan sistem limbik dengan ritual. Salah satu karakteristik dari ritual ialah melahirkan kondisi emosi, dan pusat emosi terletak di sistem limbik. ${ }^{3}$

Kegiatan ritual motorik seperti menari, atau menyanyi dalam sebuah seremoni tertentu memberikan pengaruh signifikan pada pusat emosi di sistem limbik. Akibat keterlibatan pusat emosi dan sistem saraf otonom, pelaku ritual dapat mengalami keadaan yang menyenangkan dan menggembirakan. Berbagai riset menunjukkan mereka yang mempraktikan perilaku ritual tertentu seperti pelayanan keagamaan, meditasi, dan kegiatan fisik tertentu memiliki fungsi fisiologi tubuh yang baik serta perubahan sistem kekebalan tubuh yang positif. Fungsi-fungsi ini diatur oleh hipotalamus, yang juga merupakan bagian dari sistem limbik. ${ }^{3}$

Salah satu bentuk ritual yang sering dilakukan ialah doa. Dari perspektif neurobiologi, doa yang dipanjatkan memberikan efek berupa pengalaman emosi, dan transendensi yang dalam dan kuat. Isi doa memberi efek langsung terhadap pusat emosi otak yaitu sistem limbik. ${ }^{1}$ Herbet Benson, seorang ilmuwan dari Harvard University, melakukan penelitian tentang doa untuk memahami pikiran seseorang terhadap tubuhnya. Benson mendokumentasikan MRI brain scan yang menunjukkan perubahan fisik yang terjadi pada tubuh seseorang pada saat berdoa. Hasil MRI memperlihatkan gambaran aktivitas otak

Tabel 4. Hubungan sistem limbik dengan ritual berdasarkan SPSS

\begin{tabular}{|c|c|c|c|}
\hline Spearman's rho & & Sistem Limbik & Ritual \\
\hline \multirow{4}{*}{ Sistem Limbik } & $\begin{array}{l}\text { Correlation } \\
\text { Coefficient }\end{array}$ & 1.000 & $-.346^{*}$ \\
\hline & Sig. (2-tailed) & & .013 \\
\hline & $\mathrm{N}$ & 51 & 51 \\
\hline & $\begin{array}{l}\text { Correlation } \\
\text { Coefficient }\end{array}$ & $-.346^{*}$ & 1.000 \\
\hline Ritual & $\begin{array}{c}\text { Sig. (2-tailed) } \\
\mathrm{N}\end{array}$ & $\begin{array}{c}.013 \\
51\end{array}$ & $\dot{51}$ \\
\hline
\end{tabular}

*Correlation is significant at the 0.05 level (2-tailed). 

yang kompleks dimana sistem limbik menjadi lebih santai serta aktivitas fisiologis menjadi lebih merata. ${ }^{13}$

\section{SIMPULAN}

Dari hasil penelitian ini disimpulkan terdapatnya hubungan bermakna antara kinerja otak dan spiritualitas, dalam hal ini sistem limbik dan ritual, yang diukur dengan menggunakan ISHA pada pemimpin agama di kota Tomohon. Hal ini menunjukkan bahwa pemimpin agama di kota Tomohon aktif dalam mengikuti kegiatan-kegiatan ritual dan mempunyai fungsi sistem limbik yang bekerja baik.

\section{UCAPAN TERIMA KASIH}

Ucapan terima kasih ditujukan kepada dr. Shane H. R. Ticoalu, MKes, AIFO dan dr. Marie M. Kaseke, MKes serta kepada semua pihak yang telah memberikan ide ataupun gagasan kepada penulis baik secara langsung maupun tidak langsung.

\section{DAFTAR PUSTAKA}

1. Pasiak T. Manajemen Kecerdasan: Memberdayakan IQ/EQ/SQ untuk Kesuksesan Hidup. Bandung: Mizan, 2006.

2. Wattimena R. Memperkenalkan status neurosains [cited 2012 Oct 15]. Available from: http://www.wima.ac.id/index.php? $r=$ university/article\&id=1057.

3. Pasiak T. Tuhan dalam Otak Manusia: Mewujudkan Kesehatan Spiritual Berdasarkan Neurosains. Bandung: Mizan, 2012.
4. Pasiak T. Gangguan Bipolar dan Pendekatan Neurosains Spiritual. PDSKJI Cabang Surabaya. Surabaya, 2012.

5. Pasiak T. Neuron to Nation. Dewan Riset Nasional-BPPT. Disampaikan di Jakarta, Agustus 2012.

6. Hamid AY. Bunga Rampai Asuhan Keperawatan. Jakarta: Penerbit Buku Kedokteran EGC, 2008.

7. Mikail B. Spiritualitas dan efeknya terhadap penyembuhan [cited 2012 Oct 15]. Available from: http://health.kompas.com/read/2012/01/16/ 10441523/Spiritualitas.dan.Efeknya.Terhad ap.Penyembuhan.

8. Kinarsih KD, Wahyuningsih A. Peran pendampingan spiritual terhadap motivasi kesembuhan lanjut usia. Jurnal STIKES 2012;5(1):8-9.

9. Mabena N, Moodley P. Spiritual meanings of illness in patients with cervical cancer. South African Journal of Psychology. 2012;42(3):305-9.

10. Pasiak T. Neurosains, Spiritualitas dan Psikoterapi. POKDI Psikoterapi PP PDSKJI. Disampaikan pada Konas Psikoterapi. Jakarta, Mei 2012.

11. Pasiak T. Assesment Spritualitas Otak. Launching CNET. Disampaikan di Aula UIN Kalijaga Jogja, 26 Januari 2012.

12. Dermawan A. Spritualitas versus keadilan [cited 2012 Des 7]. Available from: http://djemiwowiling.blogspot.com/2012/1 2/spritualitas-versus-keadilan.html.

13. Kinarsih S. Dampak berdoa bagi kesehatan [cited 2012 Des 27]. Available from: http://mindhealingtherapy. blogspot. com/2010/11/berdoa-dan-dampak-positipyang.html 